\title{
UPAYA PENINGKATAN KOMPETENSI GURU DALAM PEMBUATAN SKENARIO PEMBELAJARAN INOVATIF MELALUI IHT (IN HOUSE TRAINING) DI SD NEGERI 1 WIROTAMAN
}

\author{
Bambang Dwi Subekti \\ Kepala SD Negeri 1 Wirotaman, Kec. Ampelgading Kab. Malang \\ bambang.ds.ks@gmail.com
}

\begin{abstract}
Considering the condition of teachers in Elementary School Wirotaman 1 Ampelgading Malang, which at the moment most of them still use the Learning Implementation Plan copypaste results, and remember the importance of making innovative learning scenarios in a Learning Implementation Plan, on this occasion researchers intend to improve teacher competency especially in making innovative learning scenarios through In House Training in Elementary School Wirotaman 1 Ampelgading Malang"

Based on the data obtained in the activity program implementation instrument in Cycle I which includes preparation, implementation, monitoring and evaluation activities, and reflection, it can be seen that the final score amounted to 80 with the Good category. In the implementation of Cycle II, the final number obtained was 84 with the Very Good category.
\end{abstract}

Keyword: Improvement, Teacher Competence, In House Training

\section{PENDAHULUAN}

Kepala Sekolah memiliki dua peran strategis sebagai leader dan manajer di sekolah. Ketika perencanaan pendidikan dikerjakan dan struktur organisasi persekolahannyapun disusun guna memfasilitasi perwujudan tujuan pendidikan, serta para anggota organisasi, pegawai atau karyawan dipimpin dan dimotivasi untuk mensukseskan pencapaian tujuan, tidak dijamin selamanya bahwa semua kegiatan akan berlangsung sebagaimana yang direncanakan, dan dikelola dengan baik, di antaranya adalah pengetahuan tentang manajemen. Dengan kemampuan dalam mengelola ini nantinya akan dijadikan sebagai pegangan cara berfikir, cara mengelola dan cara menganalisis sekolah dengan cara berpikir seorang manajer. Kepala sekolah harus mampu menunjukkan perilakunya dan mampu untuk mengidentifikasi dan mengembangkan jenis-jenis input sekolah; mengembangkan proses sekolah (proses belajar mengajar, pengkoordinasian, pengambilan keputusan, pemberdayaan, pemotivasian, pemantauan, pensupervisian, pengevaluasian dan pengakreditasian).

Berdasarkan hasil pengamatan peneliti selama menjabat menjadi Kepala SD Negeri 1 Wirotaman Kecamatan Ampelgading Kabupaten Malang, teridentifikasi bahwa kompetensi supervisi peneliti masih harus terus diasah, terutama dalam mempengaruhi, menggerakan, mengembangkan dan memberdayakan pihak-pihak terkait, baik secara individu maupun kelompok sebagai upaya untuk meningkatkan kompetensi guru dalam pembuatan skenario pembelajaran inovatif.

Mempertimbangkan adanya kondisi guru di SD Negeri 1 Wirotaman Kecamatan Ampelgading Kabupaten Malang yang pada saat ini sebagian besar masih 
mempergunakan Rencana Pelaksanaan Pembelajaran (RPP) hasil copy - paste, serta mengingat pentingnya pembuatan skenario pembelajaran inovatif dalam sebuah Rencana Pelaksanaan Pembelajaran (RPP), maka pada kesempatan ini peneliti bermaksud meningkatkan kompetensi guru terutama dalam pembuatan skenario pembelajaran inovatif melalui IHT (In House Training) di SD Negeri 1 Wirotaman Kec. Ampelgading Kab. Malang"

Berdasarkan latar belakang tersebut di atas, maka tujuan Penelitian Tindakan Sekolah (PTS) ini adalah: (1) untuk mengetahui pelaksanaan IHT (In House Training) sebagai upaya untuk meningkatkan kompetensi guru di SD Negeri 1 Wirotaman Kec. Ampelgading Kab. Malang, terutama dalam pembuatan skenario pembelajaran yang bersifat inovatif; dan (2) untuk mengidentifikasi adanya peningkatan kompetensi guru di SD Negeri 1 Wirotaman Kec. Ampelgading Kab. Malang, terutama dalam pembuatan skenario pembelajaran yang bersifat inovatif melalui kegiatan IHT (In House Training)

\section{METODE PENELITIAN}

\section{A. Lokasi Penelitian}

Lokasi penelitian ini yaitu SD Negeri 1 Wirotaman Kecamatan Ampelgading Kabupaten Malang. Dari aspek "pelaku" adalah terdiri dari peneliti dan guru-guru yang terlibat dalam pembuatan skenario kegiatan pembelajaran.

\section{B. Waktu Penelitian}

Penelitian Tindakan Sekolah ini dilaksanakan selama 2 kali pertemuan, yakni pada tanggal 17 Oktober 2018 untuk pelaksanaan kegiatan IHT (In House Training) Siklus I dan tanggal 18 Oktober
2018 untuk pelaksanaan kegiatan IHT (In House Training) Siklus II.

\section{Subyek Penelitian}

Sumber yang dapat memberikan informasi dan dapat membantu perluasan teori merupakan subyek penelitian (Bogdan dan Biklen, 1990). Subyek penelitian ini adalah seluruh guru SD Negeri 1 Wirotaman Kec. Ampelgading Kab. Malang dalam pembuatan skenario kegiatan pembelajaran yang inovatif melalui kegiatan IHT (In House Training)

\section{Perencanaan Penelitian}

1. IHT (In House Training) Siklus I

Pada tahap persiapan, calon kepala sekolah melakukan wawancara dengan guru senior untuk memperoleh informasi mengenai pola serta kecenderungan guru sasaran dalam membuat Rencana Pelaksanaan Pembelajaran (RPP) yang telah diterapkan selama ini, serta untuk mengumpulkan beberapa bukti fisik berupa Rencana Pelaksanaan Pembelajaran (RPP) hasil buatan sendiri guru yang menjadi sasaran IHT (Bukti fisik berupa RPP hasil buatan guru sendiri sebagaimana terlampir). Bersamaan dengan itu, calon kepala sekolah mengutarakan rencananya untuk melaksanakan program IHT sekaligus menginformasi jadwal pelaksanaan IHT dan materi yang akan disampaikan. Selanjutnya dengan menyaring berbagai informasi dari beberapa referensi yang dijadikan sumber, calon kepala sekolah membuat modul pelatihan yang berisi langkah-langkah pembuatan RPP yang lengkap (Modul Pelatihan Pembuatan RPP Versi Kurikulum 2013 sebagaimana terlampir). Di samping itu 
calon kepala sekolah juga mempersiapkan soal pre test yang akan dipergunakan untuk mengukur pengetahuan dan kemampuan guru sasaran sebelum dilaksanakan IHT.

Agar pelaksanaan kegiatan IHT nantinya dapat berjalan dengan lancar, maka pada kesempatan ini calon kepala sekolah menjalin kerjasama dengan pihak-pihak terkait untuk membentuk Panitia IHT melalui kegiatan rapat (Berita Acara dan Daftar Hadir Rapat Pembentukan Panitia Kegiatan IHT sebagaimana terlampir). Sedangkan untuk menyampaikan materi pelatihan, calon kepala sekolah membuat membuat modul Penyusunan RPP yang dibagikan pada seluruh peserta IHT, sehingga meskipun tidak dilengkapi sarana berupa LCD Proyektor, akan tetapi materi IHT dapat disampaikan secara merata kepada seluruh peserta. Di samping itu penataan ruangan serta persiapan perlengkapan seperti mike wearless, dan lain-lain, juga perlu disiapkan.

Selain melibatkan kepala sekolah serta guru sasaran, calon kepala sekolah juga meminta bantuan Pengawas SD di lingkup Dinas Pendidikan Kecamatan Ampelgading untuk memberikan bimbingan dan masukan dalam rangka pelaksanaan IHT yang akan diadakan.

2. IHT (In House Training) Siklus II

Berbeda dengan kegiatan persiapan pada Siklus I, pada Siklus II ini calon kepala sekolah didampingi oleh Pengawas Sekolah sebagai narasumber mengajak guru sasaran untuk mengevaluasi hasil pembuatan RPP masing-masing, selanjutnya mengadakan refleksi. Pada pelaksanaan Siklus II ini, disamping mempersiapkan
RPP hasil buatan guru sasaran sebagaimana telah ditugaskan pada pelaksanaan IHT Siklus I, calon kepala sekolah juga mempersiapkan soal post test. Adapun soal post test dalam hal ini dibuat sama dengan soal pre test, hal ini sengaja dilakukan dengan alasan agar dapat dibuat perbandingan diantaranya keduanya (perbandingan hasil pengerjaan pre test dengan post test).

\section{HASIL DAN PEMBAHASAN}

\section{A. Pelaksanaan IHT (In House Training) Siklus I}

Kegiatan ini diawali dengan pelaksanaan Pre Test IHT (pada pukul 11.00 WIB - 11.30 WIB), selanjutnya guru sasaran diberi modul mengenai pembuatan RPP yang telah dibuat oleh calon kepala sekolah. Pada kegiatan inti, Pengawas Sekolah didampingi oleh calon kepala sekolah menyampaikan materi mengenai langkah-langkah pembuatan RPP beserta segala kelengkapannya mempergunakan modul tentang Penyusunan RPP. Adapun jadwal kegiatan pelatihan untuk Siklus I ini dilakukan pada hari Rabu, yaitu tanggal 17 Oktober 2018, mulai jam 11.00 WIB sampai dengan jam 14.00 WIB (Notula pelaksanaan IHT Siklus I dan Daftar Hadir Pelaksanaan IHT Siklus I sebagaimana terlampir)

Untuk menguji kompetensi guru terhadap penguasaan materi yang telah disampaikan, guru sasaran secara berkelompok diberi lembar kerja guna melakukan analisis guna membedakan antara RPP hasil buatan guru sendiri dengan RPP versi Kurikulum 2013 yang terdapat pada modul. Setelah mengetahui RPP hasil buatan guru tersebut, calon kepala sekolah meminta guru sasaran secara berkelompok untuk mengidentifikasi kekurangan yang menonjol yang terdapat pada RPP hasil buatan guru sendiri. 
Pada akhir kegiatan IHT Siklus I, guru sasaran diberi tugas untuk membuat RPP yang wajib dikumpulkan pada pelaksanaan IHT Siklus II, yakni pada hari Kamis, tanggal 18 Oktober 2018. Hasil pembuatan RPP oleh guru sasaran tersebut, nantinya akan dipergunakan sebagai bahan evaluasi dan refleksi.

\section{B. Monev (Monitoring dan Evaluasi) pada IHT (In House Training) Siklus I}

Pada tahap monev, guru yang terlibat dalam kegiatan melakukan pengisian instrumen monev untuk mengetahui kompetensi mereka dalam penguasaan materi yang telah disampaikan oleh narasumber serta kesan mereka mengenai kegiatan IHT yang telah diikuti. Sebelum melakukan pengisian instrumen, calon kepala sekolah memberikan penjelasan tentang cara pengisian instrumen.

\section{Refleksi Hasil IHT (In House Training) Siklus I}

Hasil yang diperoleh pada saat uji kemampuan awal dikumpulkan dan dianalisis dalam tahap refleksi agar dapat dipergunakan sebagai acuan dalam pelaksanaan pelatihan selanjutnya.

\section{Hasil IHT (In House Training) Siklus I}

Hasil yang diharapkan dari pelatihan pada kegiatan IHT Siklus I ini, diharapkan guru sasaran dapat meningkatkan kompetensinya dalam proses belajar mengajar, yakni dengan cara mengidentifikasi kekurangan-kekurangan yang terdapat dalam Rencana Pelaksanaan Pembelajaran (RPP) hasil buatan guru sendiri. Melalui kegiatan mengidentifikasi ini, diharapkan dapat dijadikan sebagai bahan evaluasi, guna mengembangkan ide dan persepsi awal mengenai pembuatan RPP yang lengkap dan baik.

\section{E. Pelaksanaan IHT (In House Training) Siklus I \\ IHT Siklus II ini dilaksanakan pada} hari Kamis, tanggal 18 Oktober 2018 mulai pukul 11.00 WIB - 13.30 WIB (Notula pelaksanaan IHT Siklus II dan Daftar Hadir Pelaksanaan IHT Siklus II sebagaimana terlampir)

Pada awal kegiatan IHT Siklus II, Pengawas Sekolah sebagai narasumber didampingi calon kepala sekolah mengajak guru sasaran untuk mengevaluasi hasil pembuatan RPP masing-masing yang dibuat berdasarkan tugas pada kegiatan IHT Siklus I, yakni pada hari Rabu, tanggal 17 Oktober 2018.

Berdasarkan evaluasi yang telah dilakukan pada tahap awal, maka pada kegiatan inti, guru sasaran diajak bersamasama untuk melakukan refleksi guna mengetahui kelebihan dan kekurangan yang terdapat dalam RPP buatannya.

Pada kegiatan akhir, guru sasaran mengerjakan post test, yakni pada pukul 11.00 WIB - 11.30 WIB. Sebagaiman telah disampaikan sebelumnya bahwa soal post test dibuat sama dengan soal pre test dengan harapan agar nantinya dapat dibuat perbandingan antara hasil jawaban guru sasaran saat pre test dengan saat post test, sehingga dapat menjadi bahan pertimbangan guna mengetahui signifikasi hasil kegiatan IHT yang telah dilakukan. Sebelum kegiatan IHT diakhiri, guru sasaran diberi tugas untuk membuat RPP yang wajib dikumpulkan pada hari Sabtu, tanggal 20 Oktober 2018. 


\section{F. Monev (Monitoring dan Evaluasi) pada IHT (In House Training) Siklus II}

Sebagaimana pada pelaksanaan IHT Siklus I, pada kegiatan IHT Siklus II ini pun guru sasaran juga melakukan pengisian instrumen monev untuk mengetahui kompetensi mereka dalam penguasaan materi yang telah disampaikan oleh narasumber serta kesan mereka mengenai kegiatan IHT yang telah diikuti. Sebelum melakukan pengisian instrumen, calon kepala sekolah memberikan penjelasan tentang cara pengisian instrumen (Instrumen Monev Siklus II sebagaimana terlampir)

\section{G. Refleksi IHT (In House Training) Siklus II}

Hasil yang diperoleh dari pengisian instrumen monev selanjutnya dianalisis dalam tahap refleksi untuk mengetahui apakah terdapat kemajuan/peningkatan kompetensi guru sasaran dengan membandingkan hasil pengetahuan dan kesan guru sasaran mengenai kegiatan yang telah diikuti, yakni pada pelaksanaan IHT Siklus I dengan IHT pada Siklus II.

\section{H. Hasil IHT (In House Training) Siklus II}

Hasil yang diharapkan dari pelatihan pada kegiatan IHT Siklus II ini, diharapkan guru sasaran dapat meningkatkan kompetensinya dalam proses belajar mengajar, yakni melalui pembuatan skenario pembelajaran inovatif dalam Rencana Pelaksanaan Pembelajaran (RPP) yang lengkap dan terencanaan dengan baik. Peningkatan kompetensi diharapkan dapat diterapkan secara langsung dalam mempersiapkan kegiatan pembelajaran, dan pada akhirnya akan meningkatkan kualitas pembelajaran bagi peserta didik/siswa.
Berdasarkan data yang diperoleh dalam instrumen keterlaksanaan program kegiatan pada Siklus I yang meliputi kegiatan persiapan, pelaksanaan, monitoring dan evaluasi, dan refleksi dapat diketahui bahwa jumlah nilai akhir sebesar 80 demgan kategori Baik. Pada pelaksanaan Siklus II, jumlah nilai akhir yang diperoleh sebesar 84 dengan kategori Amat Baik.

\section{SIMPULAN DAN SARAN}

\section{A. Simpulan}

Dari pengumpulan data, analisa data, dan hasil pembahasan, maka dapat ditarik kesimpulan sebagai berikut:

1. Pada dasarnya pelaksanaan IHT (In House Training) sebagai upaya untuk meningkatkan kompetensi guru di SD Negeri 1 Wirotaman Kec. Ampelgading Kab. Malang, terutama dalam pembuatan skenario pembelajaran yang bersifat inovatif dibagi menjadi 2 (dua) kali pertemuan/2 Siklus. Pada Siklus I, di awal pelaksanaan IHT, guru terlebih dahulu mengerjakan pre test. Setelah itu guru sebagai peserta IHT mendapatkan materi mengenai langkah-langkah pembuatan RPP beserta segala kelengkapannya mempergunakan modul tentang Penyusunan RPP berdasarkan modul yang disampaikan oleh pengawas sekolah. Pada kegiatan akhir, guru mengerjakan post test. Sebelum kegiatan IHT diakhiri, guru sasaran diberi tugas untuk membuat RPP yang wajib dikumpulkan pada keesokan harinya

2. Berdasarkan data yang diperoleh dalam instrumen keterlaksanaan program kegiatan pada Siklus I yang meliputi kegiatan persiapan, pelaksanaan, monitoring dan evaluasi, dan refleksi dapat diketahui bahwa terdapat 
peningkatan kompetensi guru di SD Negeri 1 Wirotaman

\section{B. Saran}

Berdasarkan hasil penelitian yang telah dilakukan, maka disarankan agar kepala sekolah dapat melakukan eksplorasi seluas-luasnya guna meningkatkan kemampuan mempengaruhi, menggerakan, mengembangkan dan memberdayakan (4M) sebagai bentuk kompetensi dan profesionalisme kepala sekolah.

\section{DAFTAR PUSTAKA}

Aqib. Zainal. 2002. Profesionalisme Guru Dalam Pembelajaran. Surabaya: Cendikia

Arikunto, Suharsimi. 2001. Dasar-Dasar Evaluasi Pendidikan. Jakarta: Bumi Aksara

Bafadal, Ibrahim. 2003. Peningkatan Profesionalisme Guru Sekolah Dasar: Dalam Kerangka Manajemen Peningkatan Mutu Berbasis Sekolah. Jakarta: PT. Bumi Aksara

Burhanuddin. 1994. Analisis Administrasi, Manajemen dan

KepemimpinanPendidikan. Jakarta: Penerbit Bumi Aksara

Camalia, Khoirul. 2005. Manajemen Pengembangan Kompetensi

Pendidik. Tesis, tidak diterbitkan.

Malang Program Pascasarjan UIN Malang

Danim, Sudarwan. 2002. Inovasi Pendidikan dalam Upaya

Peningkatan Profesionalisme Tenaga

Kependidikan. Bandung: PT Pustaka Setia

Daryanto, M. 2001. Administrasi Pendidikan. Jakarta: PT. Rineka Cipta
Hasibuan, Malayu SP. 2001. Manajemen: Dasar, Pengertian, dan Masalah. Jakarta: Penerbit Bumi Aksara

Hayati, Arni. 2009. Guru Bermutu Pendidikan Juga Bermutu. (online), www.Fai.Uhamka.ac.id

Ibrahim Bafadal. 2008. Tuntutan Profesionalisme Kepala Sekolah. Materi Seminar Nasional "Menyongsong Era Profesionalisme Kepala Sekolah" disampaikan pada tanggal 15 Desember 2008 di Aula Utama Universitas Negeri Malang (UM)

Kusnandar. 2007. Guru Profesional. Jakarta: PT Raja Grafindo

Lazaruth, Soewadji. 1994. Kepala Sekolah dan Tanggung Jawabnya. Yogyakarta: Penerbit Kanisius

Miftah Toha. 1995. Kepemimpinan Dalam Manajemen. Jakarta: PT Raja Grafindo Persada

Moedjiarto. 2001. Sekolah Unggul: Metodologi untuk Meningkatkan Mutu Pendidikan. Jakarta: Duta Graha Pustaka

Mulyasa, E. 2004. Manajemen Berbasis Sekolah: Konsep, Strategi dan Implementasi. Bandung: Remaja Rosdakarya

Nawawi. Hadari. 1983. Administrasi Pendidikan. Jakarta: PT Gunung Agung

Purwanto, Ngalim. 1998. Administrasi dan Supervisi Pendidikan. Bandung: PT. Remaja Rosdakarya

Rahman (at all). 2006. Peran Strategis Kapala Sekolah dalam Meningkatkan Mutu Pendidikan. Jatinangor: Alqaprint

Toha, Miftah. 2005. Perilaku Organisasi Konsep dan Aplikasinya. Jakarta: PT.Raja Grafindo 
Usmara, A. (ed). 2002. Paradigma Baru Manajemen Sumber Daya Manusia. Yogyakarta: Amara Books

Wahjosumidjo. 1999. Kepemimpinan Kepala Sekolah, Tinjauan Teoritik dan Permasalahannya. Jakarta: PT Raja Grafindo Persada
Yamin, Martinis. 2006. Sertifikasi Profesi Keguruan di Indonesia. Jakarta: Gaung Persada Press

Yuniarsih, Tjutju dan Suwatno. 2008. Manajemen Sumber Daya Manusia. Bandung:

Alfabeta 